patients with and without angina and the mechanism of action of the drug remain unexplained. Further research will be needed to characterize those patients who stand most to benefit from clofibrate and to examine how these benefits are produced. It may well be, as the authors hint, that some pharmacological action other than the effect on serum lipids is important. If this can be identified, there may be other related compounds which may be more effective than clofibrate.

These trials provide a reliable base for the necessary further examination of the place of clofibrate and related compounds in ischaemic heart disease. Cautious interpretation of. this work and the maintenance of high scientific standards of design for further therapeutic trials should prevent a repetition of the unhappy history of anticoagulant therapy.

\footnotetext{
1 McMichael, J., and Parry, E. H. O., Lancet, 1960, 2, 991

2 Report of the Working Party on Anticoagulant Therapy in Coronary Thrombosis to the Medical Research Council, British Medical fournal, 1964, 2, 837.
}

\section{"All in a Working Day"}

Any junior doctor in hospital knows that his on-duty hours are long and his work too often inefficiently organized. A report just published (see Supplement, p. 87) supports this as well as showing up many more well-known weaknesses in the organization of the work of young doctors in training. For example, it shows that some of the work presently done by doctors could well be done by non-medical personnel and it also shows that the amount of time devoted to education in a week-for instance, an average of only seven minutes for doctors in accident and emergency departments in the hospitals surveyed-is pitifully small.

Carried out by the Department of Health's Management Services team on the instigation of the authors of the Cogwheel report, this report clearly spells out the many difficult problems facing junior staff. Observers closely followed the activities of 85 doctors in nine different hospitals for 7,000 hours and they showed that the average weekly duty time (including "on call") for these doctors was 88 hours 15 minutes, though actual work occupied less than 40 hours of this. Of the three areas examined-general surgery, general medicine, and accident and emergency-junior doctors in general surgery averaged seven hours a week more "on call" than their colleagues in medicine, though the working hours for the two groups were almost the same at just over 41 hours. In accident and emergency departments the contrast between "on call" and working time was more striking-about 69 and 29 hours respectively-and to remedy this the report suggests a three shift system for staffing these departments. The statistics in this report support the B.M.A.'s Hospital Junior Staffs Group Council's recent report (Supplement, 4 December, p. 55) on extra-duty payments and, in particular, justify the proposal made in that report that "on call" commitments should be reviewed. Analysing the workload between 10 p.m. and 9 a.m.-with peaks before and after midnight-the Management Services team's proposal is that "on call" rotas for surgery and medicine should be revised to reduce the number of doctors on call by $50 \%$ after 1.30 a.m., and it also recommends greater pooling of juniors in divisions as a way of giving them more time off.

Averages can be misleading, however, and flexibility is essential. Responsibility outside the normal working day is not just a question of tidily arranging names on a weekly rota. Many doctors prefer to be called out if their own patients are in trouble-particularly, for example, when a patient has had an operation that day-and rota systems must be able to cope with this situation. There is a danger that in demanding too cut and dried on-duty commitments young doctors may be undermining their own professional status. It is proper, therefore, that the report-produced independently of the Health Department's policy makers-recognizes that doctors have a responsibility for organizing their own work and, in proposing a normal duty week of 40 hours, it also says that junior doctors should "ensure that they make the most efficient use of the time available during their normal working day."

How much training do the young men get? The seven minutes a week in accident and emergency departments already referred to is bettered by surgery departments, which manage 29 minutes, while general medicine achieves one and a quarter hours on average. These depressingly low figures totally vindicate the complaints from junior staff that in most hospitals training arrangements are still woefully inadequate and subordinate to service needs. When, despite wide publicity about training deficiencies, a report like this states bluntly that (at the hospitals visited) "the amount of time identifiable as being devoted to the training, formal or informal, of junior hospital doctors was very little and in some hospitals was for all practical purposes nonexistent" then senior doctors and the Health Departments must act and quickly. It is indefensible for the N.H.S. to employ large numbers of doctors, whether from home or from overseas, in posts allegedly for training when they are nothing of the sort. Clinical discussion with senior doctors, referred to in the report, is not enough. One possible way of improving the situation and at the same time ameliorating the staffing crisis in accident and emergency departments-and the report underlines the serious problems here-would be greatly to expand the training facilities in these departments.

The authors of this report have covered a wide range of junior staff problems, many of which were highlighted four years ago by the B.M.A. in its "charter" for hospital doctors. $^{1}$ But it is the condemnation of present training facilities just as much as the report's proposals for reducing the unnecessarily long hours "on call" that the profession's representatives and the Departments must really get down to when discussions start on the junior doctors' "working day."

1 British Medical fournal Supplement, 1967, 2, 93. 